\title{
Present and future of aquatic sciences: The perspective of AIOL scientific community for a priority roadmap over the next five years
}

\author{
Francesca Alvisi,${ }^{*}$ Domenico D’Alelio ${ }^{2}$ \\ ${ }^{1}$ Institute of Marine Sciences, National Research Council, Section of Bologna, Via P. Gobetti 101, Bologna; ${ }^{2}$ Department of Integrative \\ Marine Ecology, Stazione Zoologica Anton Dohrn. Villa Comunale, 80121 Naples, Italy \\ *Corresponding author: f.alvisi@ismar.cnr.it
}

\begin{abstract}
Water issues represent an increasing societal challenge, since the $70 \%$ of Planet Earth is covered by water. The intensive use of the hydrosphere is changing the structure and functions of aquatic ecosystems and their ability to produce goods and services that are useful to humans. It is therefore necessary that the scientific community makes citizens aware of the results of scientific research on these issues and informs them about the need to intensify the study of the mechanisms that underlie the ongoing changes in aquatic ecosystems. To help meet this need, within the 23rd Congress of the Italian Association of Oceanology and Limnology (AIOL; http://www.aiol.info/), entitled "Functioning, alteration and recovery of aquatic ecosystems: the aquatic sciences to understand global change and to make the citizens aware of it" (Cagliari, Italy, 26-29 September 2017), all participants, among which some renown experts in the field of aquatic sciences, were invited to give their contribution, via a shared and bottom-up built questionnaire, in assessing a set of actions needed to achieve an adaptive and proactive management of changes that the aquatic sciences are going to face in the next five years. The results of this survey allowed us to identify a set of priorities that funding agencies should include in their economic and financial planning in the next future. Among all, we pinpoint that there is an urgent need in: (i) promoting sustainable food production by exploiting aquatic systems; (ii) diffusing an opportune spatial planning integrating ecosystem-based management approaches; (iii) developing recovery/remediation plans for contaminated sites; iv) promoting conservation of ecosystems by assessing their conservation status, first of all the water/ecosystem quality; (v) fostering the technological development of sustainable and integrated tools and procedures for environmental monitoring; (vi) developing a better forecasting capacity, particularly of extreme events, by implementing long-term research networks; and, ultimately, (vii) supporting a wider society learning processes and a more effective transfer of knowledge from science to society.
\end{abstract}

Key words: Aquatic sciences, roadmap, marine sciences, limnology, oceanography, AIOL.

Received: May 2018. Accepted: June 2018.

\section{INTRODUCTION}

The growth of human population and the consequent increasing anthropogenic impact on terrestrial and aquatic ecosystems are today societal problems perceived globally and no longer of interest for the sole scientific community. Indeed, the intensive use of the hydrosphere and of non-renewable resources, the globalization of markets and maritime transport, and other socioecological issues, are changing the structure and functions of aquatic ecosystems and their ability to produce goods and services that are useful to humans.

Inland waters contribute to the supply of clean water by absorbing or filtering pollutants such as heavy metals, excess nutrients, and pesticides and storing water that could otherwise lead to floods (Postel and Carpenter, 1997). These ecosystems are vulnerable to climate change, land-use reclamation, pollution, salinization and, ultimately, biological invasions (Williams, 2001; Likens, 2009; Vilà et al., 2010). The coastal and deep marine environments are major providers of goods and services (https://ec.europa.eu/maritimeaffairs/policy/blue growth en), such as food, fossil fuels, construction material, transport and recreation (Pauli, 2010; Silver et al., 2015). They also host invaluable biodiversity that shapes complex ecosystems and play a fundamental role in planetary biogeochemical cycles (e.g. Boero et al., 2007; Howarth et al., 2011; Gamfeldt et al., 2015; D'Alelio et al., 2016). Altogether, marine ecosystems are exposed to a plethora of threats (Crain et al 2008).

Collectively, all kinds of aquatic systems are threatened by demographic and economic growth via multiple human activities, such as agriculture, fisheries, aquaculture, shipping, urbanization and tourism (Dornburg et al., 2008; Bogdan et al., 2014).

Water issues represent an increasing societal challenge, since the $70 \%$ of Planet Earth is covered by water, and only less than $3 \%$ of this amount is freshwater. Nevertheless, the two thirds of the $35 \times 10^{6} \mathrm{~km}^{3}$ of freshwater resources of the planet are trapped at the ice caps and glaciers, whereas only one third is present in 
liquid form. The largest part of this vital resource is stored in the rocky slopes and underground water basins, with the result that only $0.2 \times 10^{6} \mathrm{~km}^{3}$ is available at the Earth's surface (Pearce, 2006). In the European Union, water scarcity and droughts already affect one third of the territory, while $44 \%$ out of the total abstraction of freshwater is used to cool thermal power plants, and $24 \%$ for irrigation. As water scarcity and droughts regularly affect large parts of the European territory, water availability and its efficient use are also issues that need to be addressed in Europe (Alpine Convention, 2009; https://ec.europa.eu/jrc/en/research-topic/water). In addition, chemical compounds used in our daily activities can travel along rivers and lakes and end up in coastal and marine environments, where they can potentially threaten the health of aquatic ecosystems, and therefore, humans (Glassmeyer et al., 2017). Finally, intensive agriculture is responsible for the degradation of the quality of surfaceand groundwater, including contamination from pesticides and nitrates (Di Guardo and Finizio, 2016; Di Guardo et al., 2017).

The degradation or even disappearance of aquatic environments put at extreme risk a wide range of important ecosystem services, negatively affecting our well-being and threating our economies. In this context, EU policies promote an integrated framework for water resource management, drawing on European experience of managing river basins and transboundary rivers, and a whole range of European approaches to water and sanitation services. In the past decades, the increasing water contamination levels led the European Commission to adopt a series of directives to regulate the over-exploitation of water resources and water pollution (i.e., the EU 'Water Framework Directive', or WFD, released on 23 October 2000 - http://ec.europa. eu/environment/water/water-framework/index en. html; the EU 'Marine Strategy Framework Directive', or 'MSFW', released on 17 June 2008 - https://water.europa.eu/marine/ policy/marine-strategy-framework-directive; the EU 'Maritime Spatial Planning Directive', or MSPD, released on 16 January 2015 https://ec.europa.eu/maritimeaffairs/ publications/maritime-spatial-planning-directive_en/). With these Directives, the EU has developed an integrated modelling framework that links environment-use, hydrological and resource-efficiency models to evaluate different scenarios and policy options in terms of efficiency and cost-effectiveness. However, scientists are being more and more frequently questioning the opportunity to update these above-mentioned strategies to keep pace with the continuous conceptual, methodological and technological advancements involving water research, starting from highfrequency monitoring itself (Brack et al., 2017; Cianelli et al., 2017; Ruggiero et al., 2018; Buttigieg et al., 2018).

In consequence of the present climatic changes driven by carbon dioxide accumulation in the atmosphere, the transition to a low-carbon economy is also one of the key priorities of the European Union. Essential to achieving this goal is the large-scale deployment of energy technologies with a low carbon-footprint. As for temperate geographical regions, while relatively scanty water quantities, in respect to the overall freshwater budget of these areas, are consumed in renewable energy operations, carbon sequestration and storage practices would require higher amounts of water for cooling and other processes than conventional fossil fuel plants of similar capacities (Lal, 2004). Measuring the impact of such technologies on water resources is one of the major contribution from The Joint Research Center of the European Commission (https://ec.europa.eu/info/ departments/joint-research-centre_en) to the EU's Blueprint to Safeguard Europe's Water Resources and the European Energy Roadmap to 2050. Moreover, extreme climate-change-driven water-related events, such as droughts and floods, can have enormous environmental, social and economic impacts (Easterling et al., 2000; Neniston et al., 2007). The EU JRC is being developing early warning, monitoring and damage assessment systems for weather-driven natural hazards, since local and transnational disasters have demonstrated that efficient risk management is of paramount importance. JRC also develops tools for assessing the effects of climate and land-use change, risk mapping and adaptation to increasingly frequent extreme events across Europe and worldwide (JRC, 2014; Thielen del Pozo et al., 2015).

In light of the deep integration between aquatic science and socio-economic-political issues, it is therefore necessary that the scientific community makes the whole society aware of the results of scientific research on these issues and of the need to intensify the study of the mechanisms that underlie the ongoing changes in aquatic ecosystems (Buytaert et al., 2014; Albrecht, 2016; Hall et al., 2016; Jacobs et al., 2016). To help meeting this need, within the 23rd Congress of the Italian Association of Oceanology and Limnology (AIOL; http://www. aiol.info/), entitled "Functioning, alteration and recovery of aquatic ecosystems: the aquatic sciences to understand global change and to make the citizens aware of it" (Cagliari, Italy, 26-29 September 2017), all participants, among which some of the leading national experts in the field of aquatic sciences, were invited to give their contribution in assessing a set of actions needed to achieve an adaptive and proactive management of changes that the aquatic sciences are going to face in the next five years, in order to match societal needs.

The 2017 AIOL Congress was organized to take stock of the most recent research results on structure and functions of terrestrial and marine aquatic ecosystems and on the importance of recovering their functions and biodiversity. The results presented during the Congress 
aimed providing inputs to implement ecosystem conservation practices, to develop virtuous and sustainable mechanisms to adapt the exploitation of natural resources to environmental and climatic changes, and to plan active recovery actions. During the Congress, to bring out the different sensitivities, experiences and competences, a specific workshop was organized where a first general discussion about the future of aquatic sciences in Italy was started. Then, to involve as many AIOL members as possible, at the end of the workshop, a questionnaire consisting of 12 questions organized in four thematic clusters was subsequently circulated online among the whole AIOL community.

In this paper, the results of the survey are presented and discussed as a contribution to the identification of the main research areas and topics that will require financial investments in the next coming years.

\section{METHODS}

The questionnaire (Tab. 1) was designed as to allow AIOL members to participate, regardless of the specific disciplines or fields of interest they dealt with, and to provide their own point of view regarding different aspects of the science-society relationship. Furthermore, the survey aimed at understanding the perception that scientists have of themselves, i.e., about their role within the society and how they would like to be envisioned by it.

The survey was composed of four clusters of questions (Tab. 1). The first one aimed at identifying the main and most current themes of scientific research related to the study of aquatic ecosystems, both marine and freshwater (Tab. 1; Cluster 1). A maximum of five possible answers was allowed for each question. The all set of given answers to this cluster is available in the Supplementary Tab. 1. The objective of the second cluster was to evaluate how the scientific community saw the role of its research within the society (Tab. 1; Cluster 2). Eight possible strengths and eight possible weaknesses of scientific knowledge, and their evaluation in terms of relative importance, i.e. fundamental/important/not important/ insignificant, were proposed (Supplementary Tab. 2). The third cluster aimed at evaluating the perception of the scientific community on social and economic challenges fueled by the current environmental changes stemming from the increasing vulnerability of aquatic environments (Tab. 1; Cluster 3). A series of possible answers has been proposed, eventually adding an empty field for free answers (Supplementary Tab. 3). The fourth cluster was used to identify the main research fields that should deserve more attention by the society, according to the AIOL community, and the motivation for the given choices. (Tab. 1; Cluster 4). For each question, a maximum of five possible answers were allowed (Supplementary Tab. 4).

The answers received for Clusters 1, 3 and 4 were grouped into sub-groups with a thematic affinity to give a synthetic view of them and to be able to make comparisons among them. Since some answers dealt with topics that were across two or more issues, we chose to assign them to the group it looked like to us more coherent with the given answer, and the results of each question were represented by a different pie chart. Thirty research scientists attended the congress workshop in Cagliari and the completed online questionnaires were thirty, too.

\section{RESULTS AND DISCUSSION}

\section{Cluster 1. Where are aquatic sciences today?}

The answers to this first group of questions were very numerous and varied in terms of highlighted issues. Some of them were very general (e.g., "climate change") other more detailed (e.g., "the ecological stoichiometry theory

Tab. 1. Structure of the survey submitted to the AIOL scientific community.

\begin{tabular}{lll}
\hline Cluster 1 & Question 1 & What are nowadays the main scientific research topics related to the study of aquatic ecosystems? \\
& Question 2 & Which topics, if any, specifically concern marine ecosystems? \\
& Question 3 & Which concern only transitional ecosystems? \\
Question 4 & And which concern freshwater environment? \\
Cluster 2 & Question 5 & Which are the strengths of scientific knowledge on these issues, and how do you evaluate their relative importance? \\
& Question 6 & Which instead are its weaknesses? \\
\hline Cluster 3 & Question 7 & Which are the social challenges, among those listed below, that will derive from the increasing vulnerability of \\
& Question 8 & European and global aquatic environments? \\
Cluster 4 & Which instead are the economic challenges? \\
& Question 9 & In which fields of basic scientific research should economic and financial resources be invested in the next 5 years? \\
& Question 11 & In which fields of applied scientific research? \\
& Question 12 & Can you list the reasons why, according to you, all these research fields should be funded?
\end{tabular}

For all the questions except for $\mathrm{n} .5$ and 6 , we asked to list or choose a maximum of five topics/items. 
bridging food webs, ecosystem metabolism and biogeochemistry") or complex (e.g., "the study of hydromorphological and chemical modifications of lake environments at high altitudes as indicators of climate changes"). Therefore, to compare them among each other and with the subsequent questions/clusters, we grouped answers in the following nine subjects (Fig. 1a-d):

i) Life sciences, including Biodiversity and Ecology issues; ii) Climatic sciences and iii) Earth sciences, concerning mainly basic research fields and some applied sciences; (iv) Toxicology was chosen for answers dealing with environmental health; v) Sustainable development, vi) Recovery and Restoration, vii) Protection and Conservation included answers specifically addressed to these topics; viii) Spatial planning included specific mentions to it as well as the development of useful applications such as modelling, monitoring and shared databases; ix) Innovation grouped only answers specifically addressed to it.

A huge set of answers mainly concerned the characterization and quantification of the physical, chemical and ecological effects of global changes, in particular the effects of climate change (e.g., global warming, desertification) on aquatic ecosystems and biological communities, as well as on biodiversity and functioning of aquatic ecosystems, and the extent of impacts in terms of ecosystem responses to such changes, the impact on the water cycle and on water resources (e.g., loss of resources, impoverishment and degradation of water quality, changes in the water cycle), and the study of water bodies as environmental indicators of these changes (e.g., water level fluctuation, coastal erosion, salt intrusion, etc.).

A second set of answers dealt with the study of biodiversity of aquatic environments and its modifications. It was suggested as a crucial present issue with a focus on its progressive impoverishment due to the strong global anthropogenic pressure in land use and resource exploitation, which led to the decrease or even disappearance of habitats and species of great ecological value. The global scale of these phenomena as well as their acceleration arose a strong interest of the scientific community: as the AIOL scientists suggest, attention to the study of the impact of global changes on the species of commercial value (including overfished stocks), the availability of fisheries resources and the possible answers in terms of production to meet the demands of global markets (e.g. aquaculture, fish and mussel farming, etc.) must be paid.

Moreover, the appearance or reappearance of potentially invasive alien species due to poorly managed introductions and fish restocking, and the increasingly frequent appearance or spread of toxic or harmful species (e.g, dangerous algal blooms, jellyfish), as a result of physical, chemical and ecological alterations of terrestrial and marine water bodies, have become themes of strong scientific and socio-economic interest (Boero et al., 2016; Hamilton et al., 2014; Meriluoto et al., 2017a; Wells and Bengt, 2018). This was confirmed by our survey's answers. At the same time, the AIOL community also suggested the need to know more and better the morphology and the geological characteristics of the basin floor of both marine (transitional, coastal and deep) and terrestrial (lakes and rivers) water bodies, as a crucial knowledge needed to better link abiotic and biotic factors in a holistic approach to the comprehension of aquatic ecosystem functioning.

Moreover, traditional fields of research more closely related to the assessment of water quality and of lasting changes induced by water use in production processes and in urban and civil environments (e.g., wastewater, industrial discharges, dispersed sources, groundwater pollution) were also pointed out. These issues have been gradually integrated by studies focused on understanding old and new phenomena related with them, such as eutrophication (e.g., use of fertilizers, sewage discharges; Schindler, 2006), acidification (e.g., increase in $\mathrm{CO}_{2}$ in atmosphere; Verspagen et al., 2014), pollution (e.g., microplastics and marine litter; Duis and Coors, 2016) and contamination (e.g., Contaminants of Emerging Concern $=$ CECs). As suggested by our survey, the assessment of the effects of these severe and widespread alterations (e.g., toxicology studies) has proven to be increasingly necessary and crucial to respond effectively and incisively to the increase in diseases and allergies and other threads on human and environmental health.

According to our respondents, the aquatic science community recently began to focus also on more transversal aspects that put the system, its functioning and relations with other neighboring systems at the center of interests. These latter issues include i) scaling of connectivity in marine and freshwater populations, ii) conservation ecology and spatial planning, iii) ecology, recovery/restoration of degraded habitats (restoration ecology), iv) integration between ecology and economic and social sciences, v) blue economy, and vi) quantification of ecosystem services. The shift towards a so-called "systems-ecology" has led to the design and development of new and increasingly sophisticated tools and technologies for the detection of early impacts, the implementation of interoperable observing systems, the increasingly widespread use of modeling, and the construction of interactive databases.

Survey results highlighted other increasingly specific and often innovative fields that recently begun to find space and interest:

- the study of the relationship between biodiversity and ecosystem functioning; 
- the microbial diversity in the deep sea and deep lakes;

- the study of viral diversity in the aquatic environment;

- biological interactions and microbial symbioses;

- 'classic' biogeochemistry, and that modeled with emerging trait-based genomics;

- ecological stoichiometry theory bridging food webs, ecosystem metabolism and biogeochemistry;

- the development of strategies to guarantee environmental sustainability (bioprospecting, circular economy, bioremediation);

- the blue biotechnology, or, the discovery and use of molecules produced by aquatic organisms that contain commercially-exploitable chemically-reactive biomolecules.

After comparing general research fields (Fig. 1a) with those specifically addressed to marine (Fig. 1b), transitional (Fig, 1c) or freshwater (Fig. 1d) aquatic ecosystems suggested by our community, we notice that (Fig. 2):

1) as for Climate and Life sciences, with emphasis on the biodiversity theme and related issues (see above), the answers are mostly homogeneous and concern all the territorial contexts suggesting the great attention of research scientists to themes pertaining climate change and its impacts on all ecosystems;
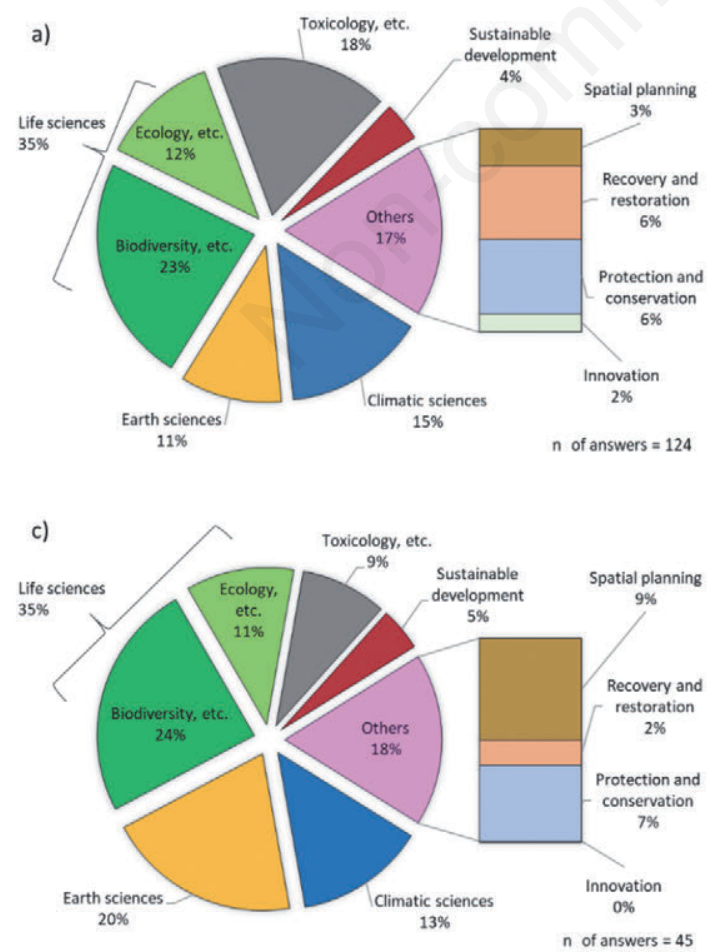

2) as for Earth sciences, a lower percentage of the general topics emerged if compared to the importance of those specifically regarding transitional environments, which underlines the need for a better understanding of the sensitivity of these latter environments to climate and environmental changes;

3) great attention is also paid to toxicology and environmental health, in particular for marine and lacustrine aquatic environments, rather than for transitional ones, which suggests the strong link between water quality and the quality of derived resources (e.g. fishery, aquaculture, drinking water, tourism, etc.);

4) a general minor interest by aquatic scientists can be seen for the other categories compared to the previous ones and even for the innovation issue, which suggests that the aquatic science community is still strongly oriented to basic scientific themes, though, at the same time, needing a greater integration and interaction with other societal subjects to improve its applicative and managerial attitude.

In this new cultural context, even the figure of the aquatic scientist is changing and is assuming multidisciplinary facets and approaches that span from sociology to biology, from physics to chemistry, from engineering to economy. The strong and driven
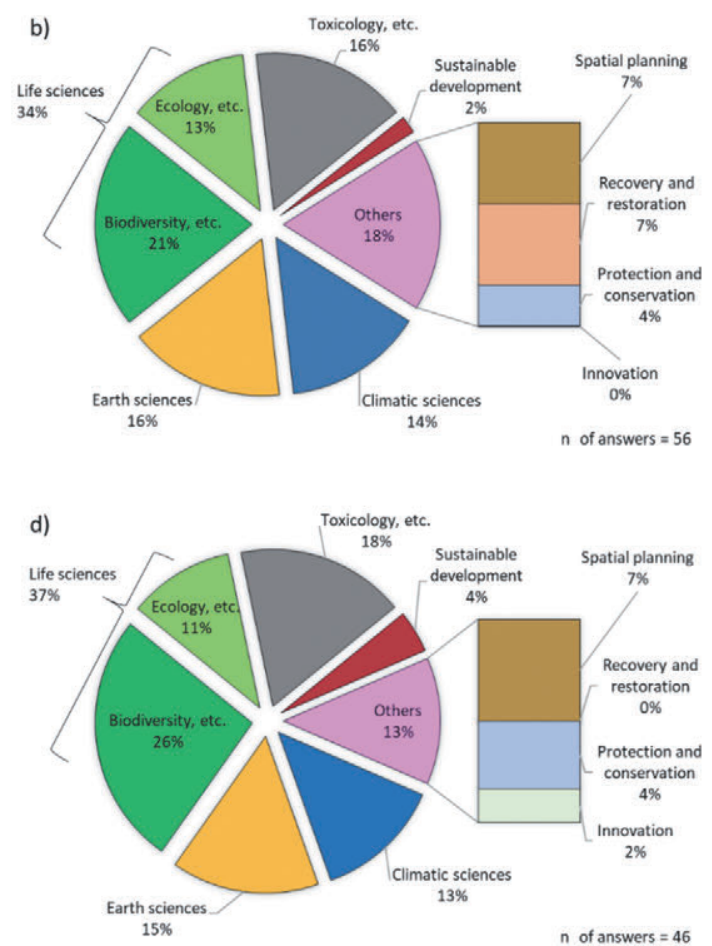

Fig. 1. Main research fields in the present scientific aquatic sciences community: a) general, b) marine, c) transitional, d) freshwater, according to AIOL community. Values are in $\%$ of received answers. 
specialization typical of researchers involved in the various disciplines of aquatic sciences, which remains necessary to understand the single steps of complex ecological processes and environmental phenomena, could clash with the need to have a holistic vision, a capacity for synthesis that would allow addressing the various scientific challenges with an eye always focused on socio-economic disciplines and on the global context. This is fostering new needs and approaches converging towards the design of multi- and interdisciplinary projects for water monitoring and management (Dickey, 2009; Tyler et al., 2009; Buttigieg et al. 2018).

\section{Cluster 2. Strengths and weaknesses of scientific knowledge}

The second survey cluster was aimed at assessing the researchers' perception about the importance of what they do. So, the questions were concerning what the actual strength points of the scientific knowledge on current aquatic science issues are and how do scientists evaluate their relative importance. The obtained answers (Fig. 3) give us the idea that most of the proposed items (Fig. 3 af) were judged important/fundamental up to $90-93 \%$ of the community, except for the last two (Fig. 3 g-h) that recorded a slightly lower (73-77\%) consensus. The scientific knowledge was considered as the main tool (Fig. 3a: fundamental $=70 \%$ ) to acquire and improve basic knowledge on aquatic systems.

An important point was also about the applied knowledge (Fig. $3 \mathrm{~b}$ : important $=60 \%$ ) seen as a tool to deal with either environmental problems or challenges. Nevertheless, the results of the survey suggest that both basic and applied research should be coupled to communication skills (Fig. 3d): half of our responding group considered communication as fundamental (47\%) to allow sharing aquatic knowledge and expertise with stakeholders aquatic knowledge and expertise, and then to translate these latter in usable, recognizable and exploitable information for the society. Equally important $(60 \%)$, even if judged as not fundamental (34\%), are the ability to network inside and outside the scientific community (Fig. $3 \mathrm{c}$ ), the management approach (Fig. 3e: $63 \%$ and $27 \%$, respectively) as well as the forecasting capacity (Fig. 3f: $64 \%$ and $30 \%$, respectively).

When moving on to socio-economic issues, the perception of the importance of scientific knowledge regarding the general well-being of the society (Fig. 3g: $60 \%$ and $13 \%$, respectively) and its economic development (Fig. 3h: $54 \%$ and $23 \%$, respectively) turns out to be even weaker. This suggests that it is not always possible tackling these aspects with the society or that the interconnection between science and society is not straightforward. We can interpret all results pertaining the above-mentioned questions as a sign that scientists' selfperception is more as being a 'carrier and transmitter of knowledge' rather than as an 'authoritative interlocutor for the society regarding prediction, management and resolution of environmental problems or challenges'.

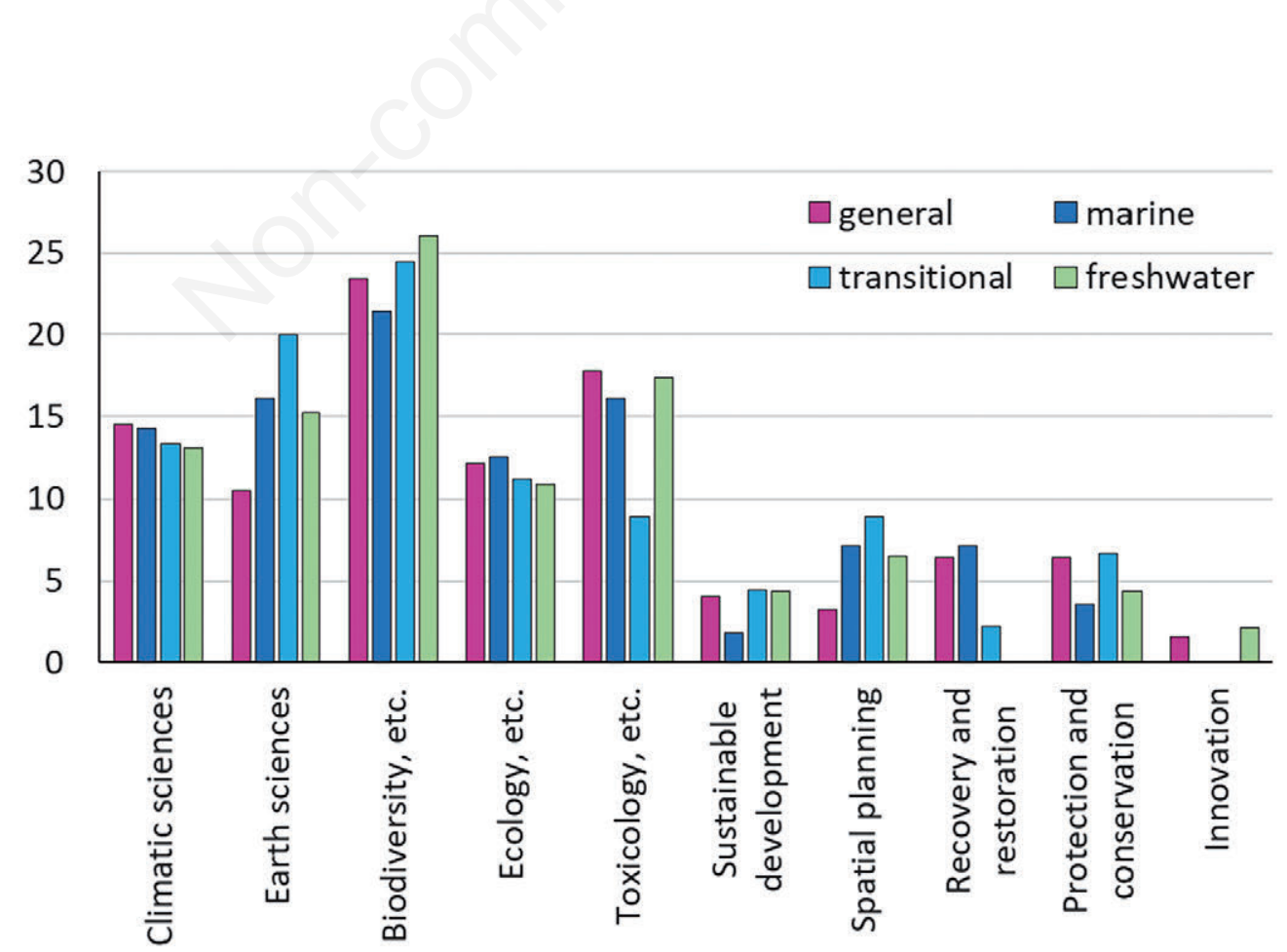

Fig. 2. Comparison among answers received for different environmental contexts. Values are in \% of received answers. 
When, in turn, we asked about the perception about scientific-knowledge weaknesses (Fig. 4), the proposed items were all judged fundamental/important, with up to $97 \%$ of consensus given to the lack of adequate policies about public research (Fig. 4f). For about one third of the interviews, gaps in knowledge (Fig. 4a) and paucity of skills (Fig. 4b) were fundamental (33\% and 30\%, respectively) and for more than a half (53\% and 54\%, respectively) these were important points of weakness, but there were also 13$17 \%$ of the respondents who considered these items not important. We can interpret these results as the common and fixed feeling by which scientists assume that new disciplines and new attitudes are always and anyway required to face new scientific challenges and topics.
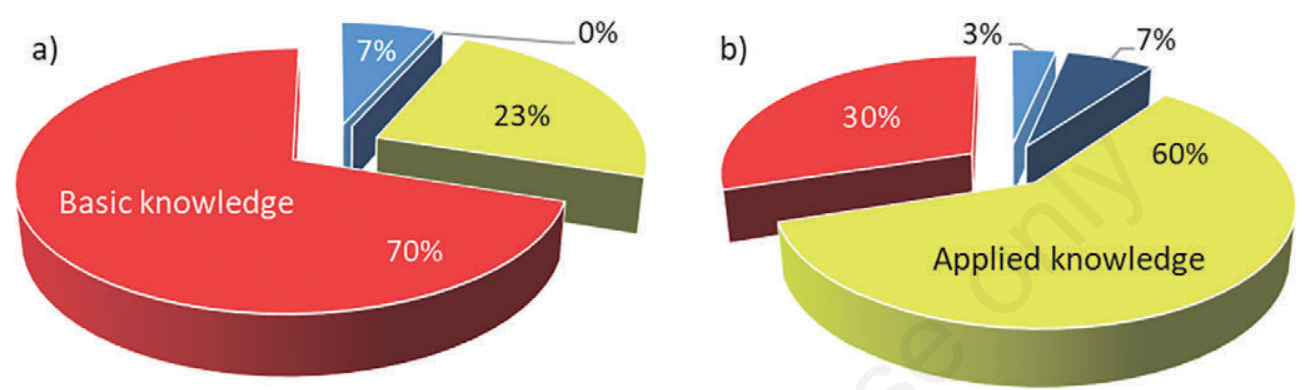

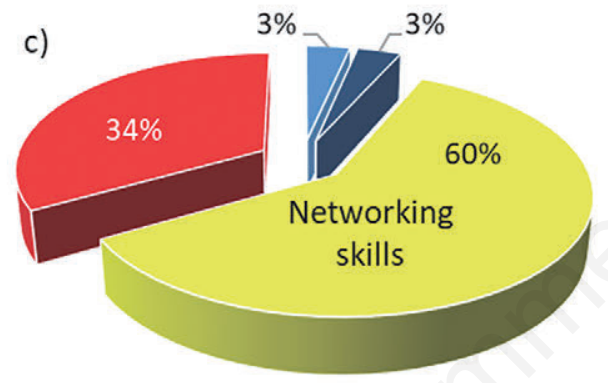

d)
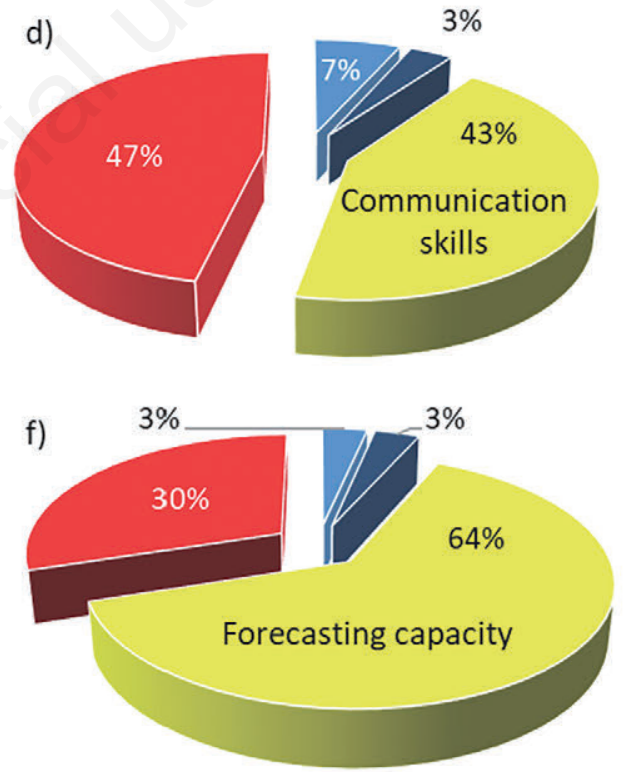

h)
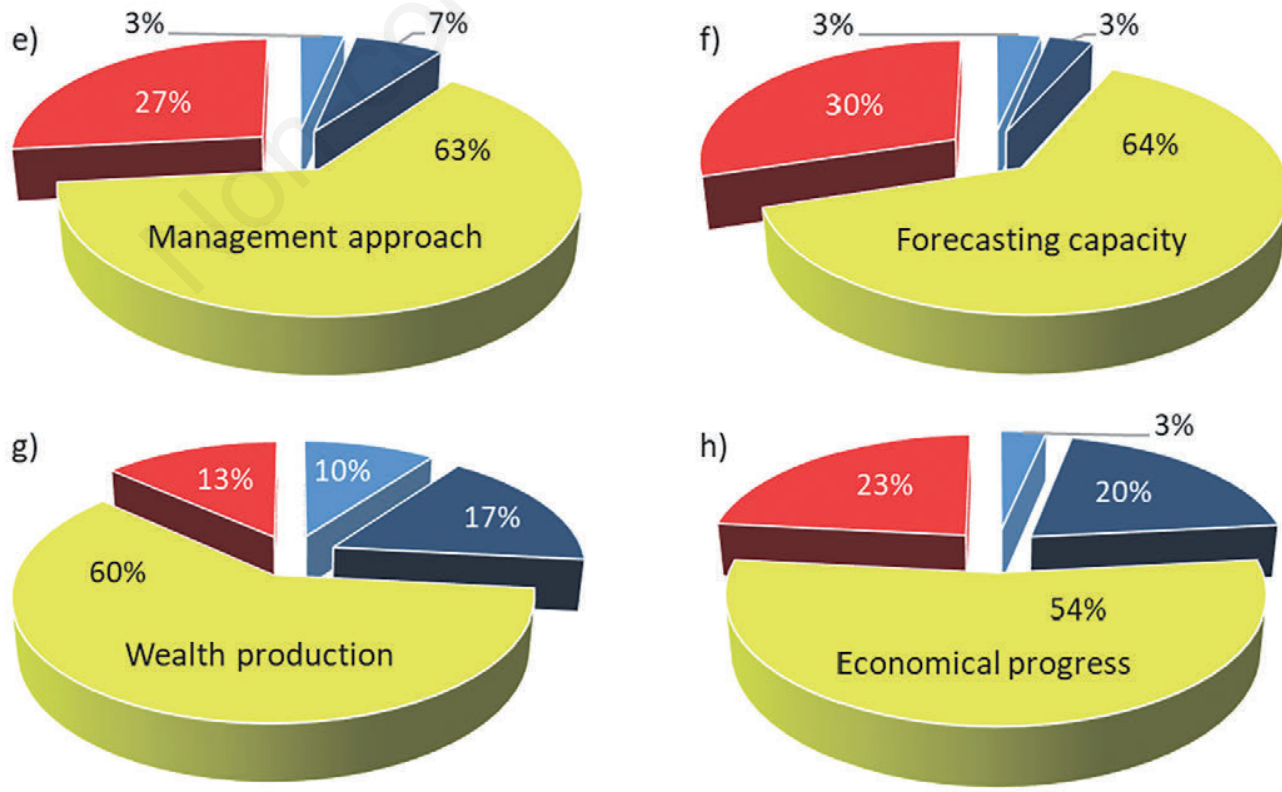

$$
\text { = Insignificant } \quad \text { Not very important }=\text { Important } \quad \text { Fundamental }
$$

Fig. 3. Perceived strengths of the scientific knowledge on aquatic science issues and rating of their relative importance. Values are in $\%$ of received answers. 
The results of the survey also indicate that for the development of scientific knowledge the lack of scientific tools (Fig. 4c) or infrastructures (Fig. 4d) are perceived as important $(70 \%$ and $67 \%$ respectively), though not so fundamental as the lack of funding (Fig. 4e) and adequate policies about research (Fig. 4f). Finally, there is a clear perception of a weak connection between science and society, partially due to the low awareness of citizens about the 'world' of research (Fig. 4g), as well as to the self-referentiality of researchers (Fig. 4h).

These answers point out the presence of two apparently opposing views on the role of the scientists, which conceal a perennial conflict. On the one hand, some researchers think they are an integral part of society, a)

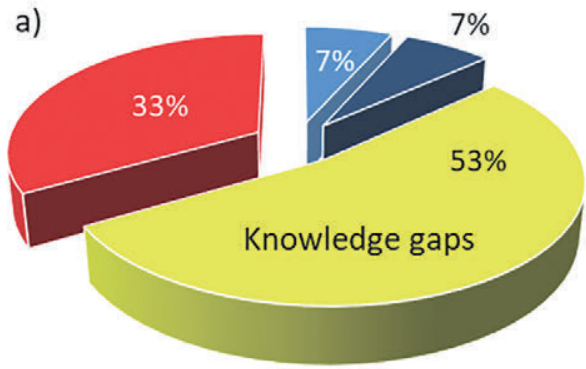

c)
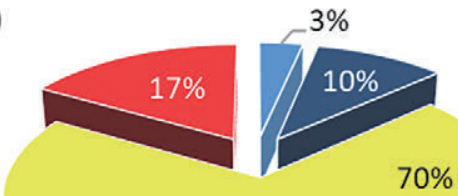

$70 \%$

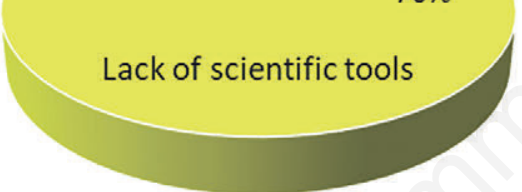

e)

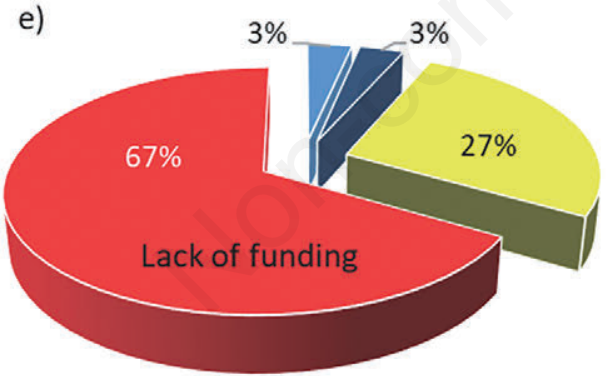

g)

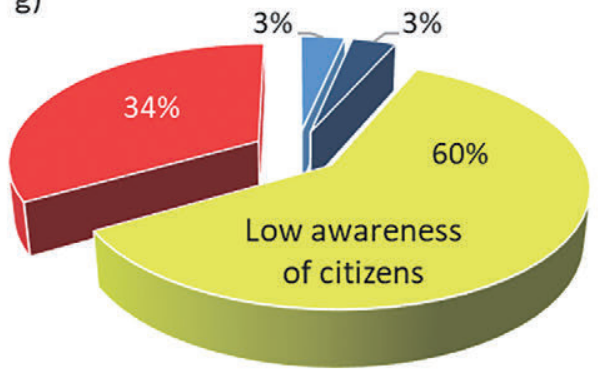

b)

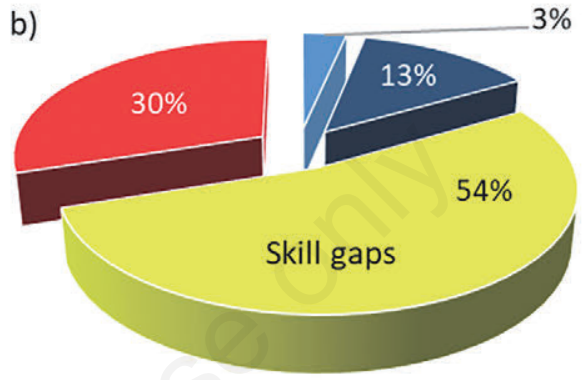

d)
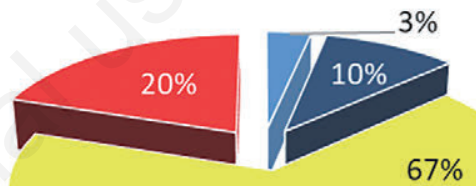

$67 \%$

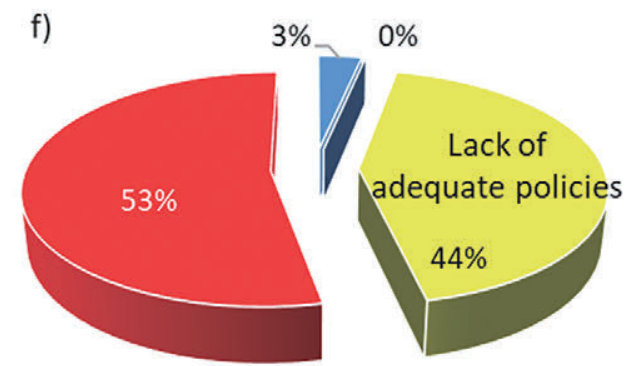

h)

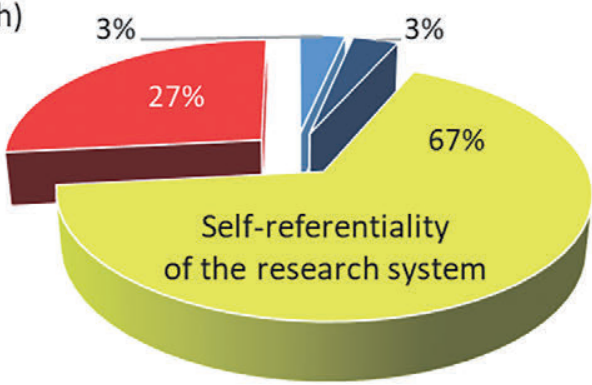

\section{- Insignificant = Not very important $=$ Important $\quad$ Fundamental}

Fig. 4. Perceived weaknesses of the scientific knowledge on aquatic science issues and rating of their relative importance. Values are in $\%$ of received answers. 
contributing with their work to increase human communities' well-being and wealth, and recognize the importance of communication skills and the value of knowledge, but also of networking and managerial skills. At the same time, they are critically aware about the tendency of scientists to be self-referent. Conversely, some other researchers think that scientific work must be only focused on acquiring specific knowledge and skills, and that citizen and society should be more interested in research, finance it more and better, to recognize its value and usefulness. Paradoxically, this group of scientists does not seem to take into full consideration their citizenship. This condition might derive from the prolonged absence of a clear research policy at national level that would cause a weakening of affinity between scientists and modern societies.

\section{Cluster 3. Perception of socio-economic challenges in a changing scenario}

To assess whether the scientists can catch the closely approaching social and economic challenges that society is going to meet in the next few years, as well as those predicted in the medium to long-term, we posed two questions concerning challenges potentially linked to the increasing vulnerability of aquatic environments at European and global levels (Cluster 3; Tab. 1).

As for social challenges, the obtained preferences
(Figs. 5 and 6) pertained some purely objective aspects, with a focus on the shortage of water resources (18\%) and drought $(5 \%)$, and on their direct impacts on land, such as a general environmental degradation (e.g., land and ecosystem degradation $=15 \%$; hydrogeological instability $=15 \%$, desertification $=7 \%$ ). Nevertheless, some of the main social aspects strictly linked to water shortage, such as ensuring health and well-being (e.g., urban settlements development, coastal and internal areas habitability, tourist-flows management, migratory-flows increase), were pointed out as equally important (29\%, Fig. 6). Lower preferences (Fig. 6) were granted to the challenges connected with the protection of natural and cultural heritage (7\%) and to the need of more Research and Development (R\&D) (4\%).

Even if these results were partially affected by the number and nature of proposed answers (see groups of Fig. 5), they testify scientists' clear perception that land degradation is the main social challenge we must face, since its effects are increasingly affecting the citizens' well-being and health. In particular, the ability to manage large flows of people caused by global environmental changes, the so-called 'environmental migrants', is already now, and will increasingly constitute a crucial challenge to ensure political stability, social equity and economic sustainability at national and international level (Science for Environment Policy, 2015).

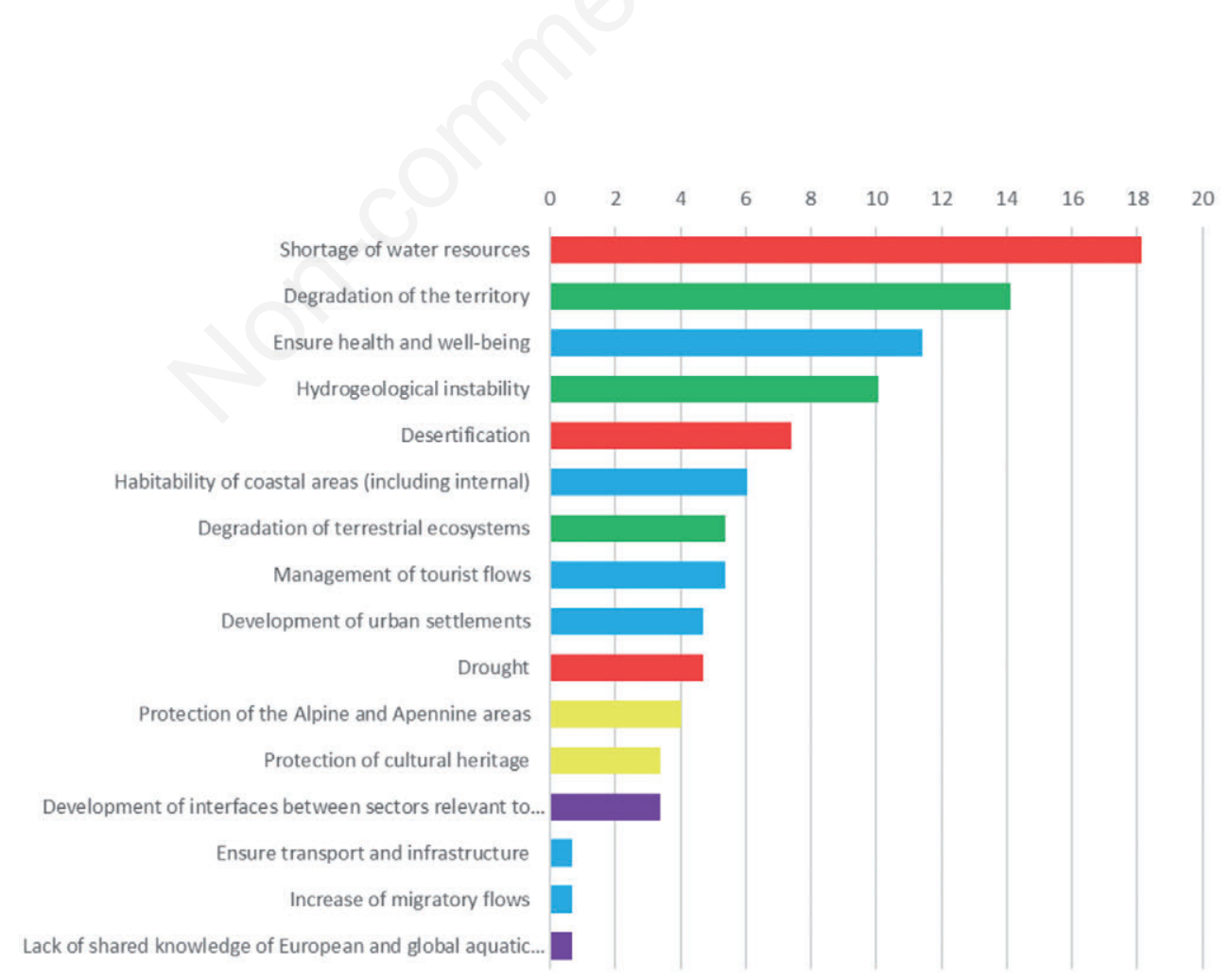

Fig. 5. Social challenges that will result from the increasing vulnerability of European and global aquatic environments and rating of their relative importance. Colors refer to groups shown in Fig. 6. Values are in \% of received answers. 
Concerning the perception of the link between the increasing vulnerability of aquatic environments and derived economic challenges, the answers highlighted the need to adopt a diffuse sustainable approach to all the main economic issues (Figs. 7 and 8), such as food production $(16 \%)$, clean energy $(10 \%)$, raw material $(10 \%)$, fishing $(6 \%)$ and agriculture $(5 \%)$, as well as a general intervention to cope with climatic changes (13\%) (Fig. 7).

Health and wellness of citizens and society as a whole (24\%; Fig. 8) have been again identified as crucial targets for the next years, including the direct management of health and wellness (10\%), demographic changes (7\%), food security (5\%), and supportive, innovative and safe communities (2\%) aspects (Fig. 7). As seen for social challenges, also in this case specific knowledge or skills challenges appear to be embedded one inside the other more than seen as separate issues (Fig. 8: $\mathrm{R} \& \mathrm{D}=1.4 \%$ ). This last result suggests that the AIOL community seems to be self-confident that what has already being done or could be done soon in terms of $\mathrm{R} \& \mathrm{D}(0.7 \%)$, and coordination and collaboration between national and international bodies $(0.7 \%)$, does not represent a challenge, but rather an established practice which only needs greater acknowledgement by means of economic and political support, as previously stated above.

\section{Cluster 4. Which aquatic science topics to finance over the next five years and why?}

To understand what, among the many disciplines of aquatic sciences, the research priority fields to invest in should be in the next few years, we submitted two questions aimed at distinguishing among basic and applied research funding priorities, and a further one specifically addressed to land management issues (Tab. 1).

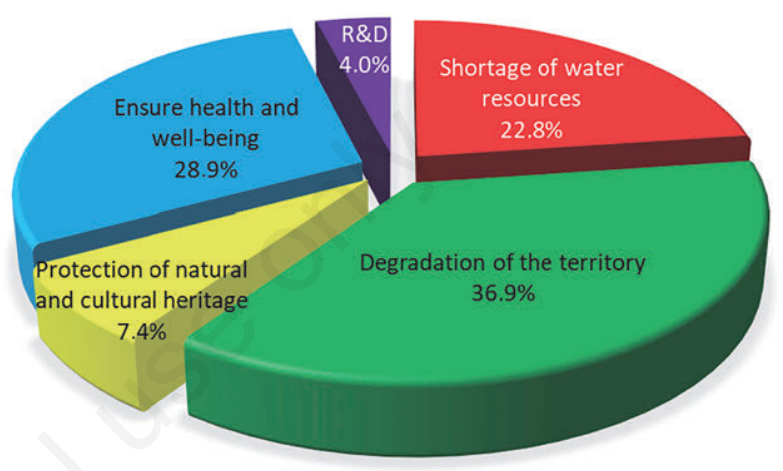

Fig. 6. Social challenges grouped by main topic and relative preferences. Values are in $\%$ of received answers.

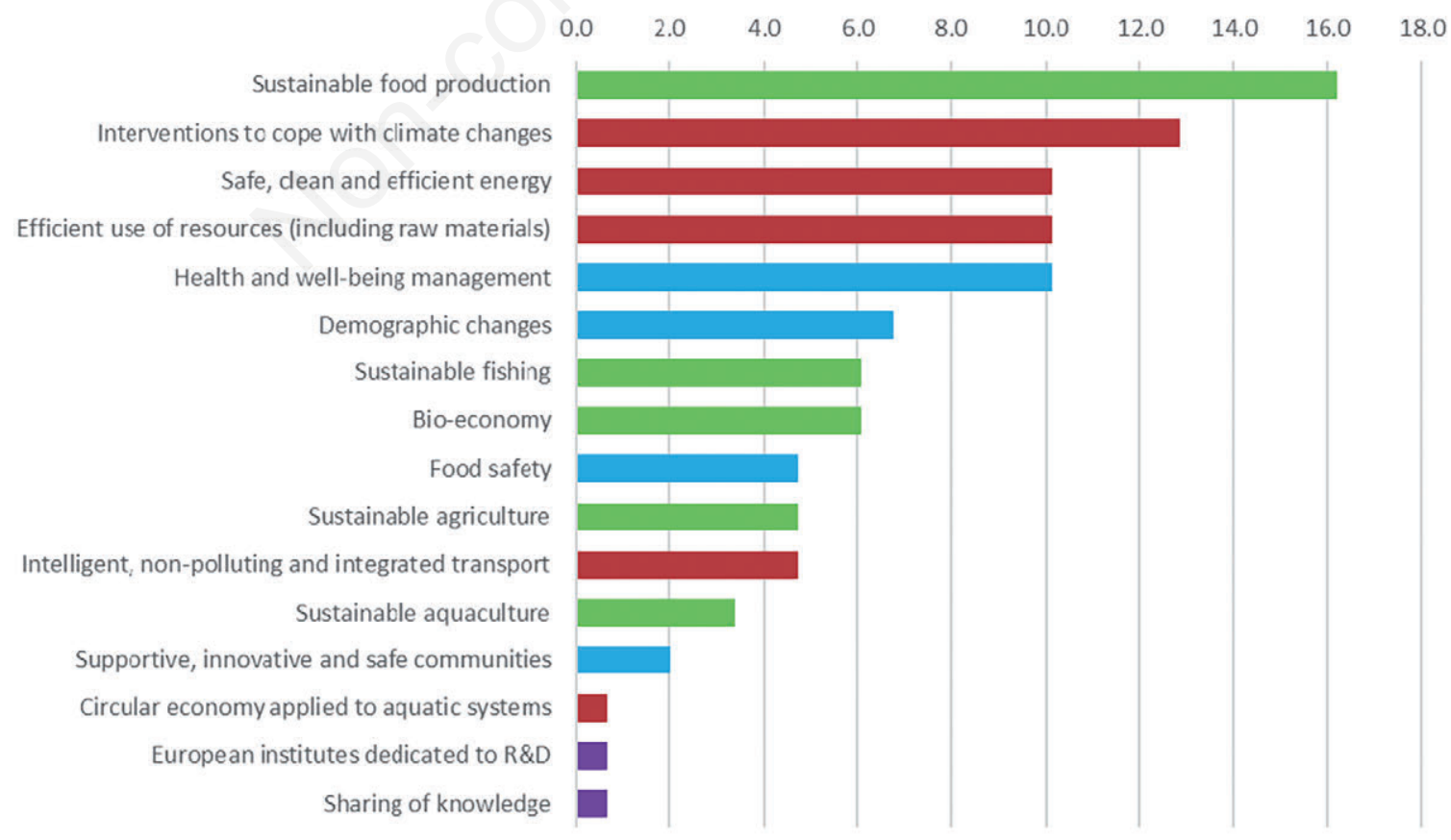

Fig. 7. Economic challenges that will result from the increasing vulnerability of European and global aquatic environments and relative preferences. Colors refer to groups shown in Figure 8. Values are in \% of received answers. 
Among basic research topics, life sciences have obtained $43 \%$ of the preferences, followed by Earth (12\%) and climate sciences $(9 \%)$, with a specific emphasis about protection and conservation (3\%), but without any mention about recovery and restoration (0\%) (Fig. 9). In addition to them, a request for a special attention to environmental health, and more properly to water toxicology, was expressed by the $12 \%$ of the sample, as well as the need to see a widespread development of a better spatial planning $(9 \%)$ with a special attention to economic/ecological/ecosystem efficiency and sustainability (8\%) (Fig. 9).

To give an idea of the complexity and variety of basic research topics that were proposed for short-term funding within the survey, we report the following items, among others, declared by the respondent.

As concerning Life sciences, the main mentioned topics were: marine and freshwater habitat characterization, biodiversity and ecology of marine and freshwater organisms, bio-ecology of commercial species, biodiversity assessment and conservation, alien species, (microbial) ecology, ecological and ecosystem processes, ecosystem functioning, relationship between biodiversity and ecosystem functioning, mechanisms of ecosystem changes over time, biomimicry, the relationship between ecology and evolution, taxonomy, genetics, metagenomics, metabolomics, altogether accounting for the $43 \%$.
In the Earth sciences sector, topics to be financed should be, among others: the response to global changes in terms of hydrological alterations, connectivity and continuity of freshwater systems, water quantity and quality, biogeochemical cycles, and a general better knowledge of lacustrine/marine geological history and evolution.

As for Climate sciences were concerned, specific funds should be dedicated to deepen our understanding

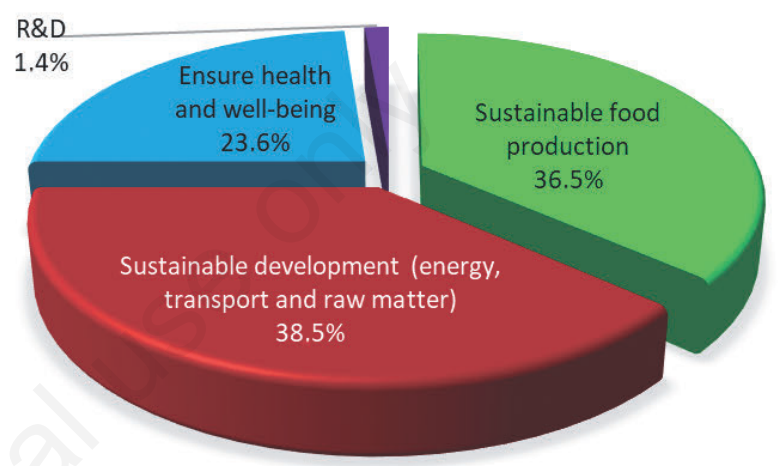

Fig. 8. Economic challenges grouped by main topic and relative preferences. Values are in $\%$ of received answers.

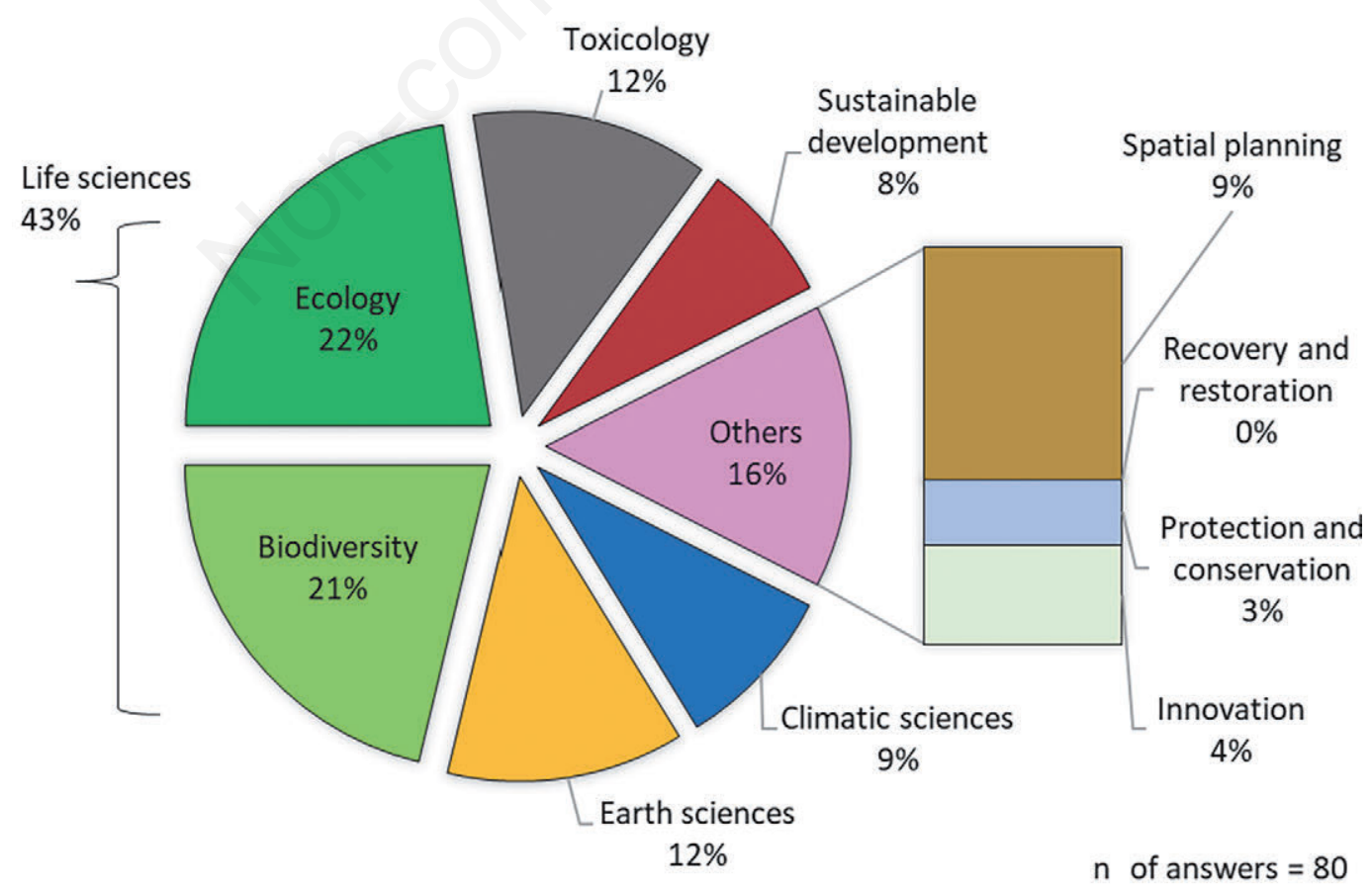

Fig. 9. Main basic research issues where to invest in in the next five years, according to AIOL community. Values are in $\%$ of received answers. 
about climate changes and on their impact on ecosystems, and to develop new approaches and strategies in order to counteract such changes (e.g., blue carbon sequestration).

As concerning the environmental management, some specific topics to be financed should be devoted to a widespread monitoring of environmental quality, with the collection of high-frequency data, building of permanent infrastructures for the observation of aquatic systems, shared and interoperable databases. The aim is to develop a better spatial planning, by including protection and management of ecosystems, but also sustainable use of biotic and abiotic resources, by improving the efficiency of water use, by promoting a closer connection with sociology and new economy, and by investing in natural capital.

A great concern was also expressed about the need to concentrate research funding on a general improvement of water quality, such as focusing on the relationships between health and pollution, on the reduction of contamination and marine litter, on the effects of pollution on the trophic webs, on the effects of CECs on structure and composition of aquatic biocoenosis, on the role of antibiotic substances, on the development of rapid microtoxin analysis to evaluate risks and effects of toxic algal blooms, etc.

Concerning applied-research topics to be funded over the next 5 years, the results of the survey (Fig. 10) clearly point out to a wider concern on the need to financially support a transition towards a sustainable development approach (26\%). We would like to point out that in the group "Sustainable development" (Fig. 10) we included only the survey answers that contained specific indications about "sustainability". However, most of the given answers, grouped in the other sub-clusters of Figure 10 , contained references and links to it, suggesting that this is felt as a major issue.

Applied research, according to the AIOL community, should be carried forward by means of a widespread use of spatial planning (14\%), based on monitoring and modelling of ecosystems characteristics, processes and functioning, run by permanent infrastructures for the observation of aquatic systems, in order to build shared and interoperable databases through the identification of reliable indicators and a common language to allow a more effective and efficient integration of ecology within economic and social sciences. Dedicated studies on recovery and restoration (13\%), as well as protection and conservation $(5 \%)$ of aquatic ecosystems, are fundamental pillars of this approach (Fig. 10), which should take advantage of innovative methods and techniques (14\%). An increasingly deeper and widespread connection between research and productive sectors that should be

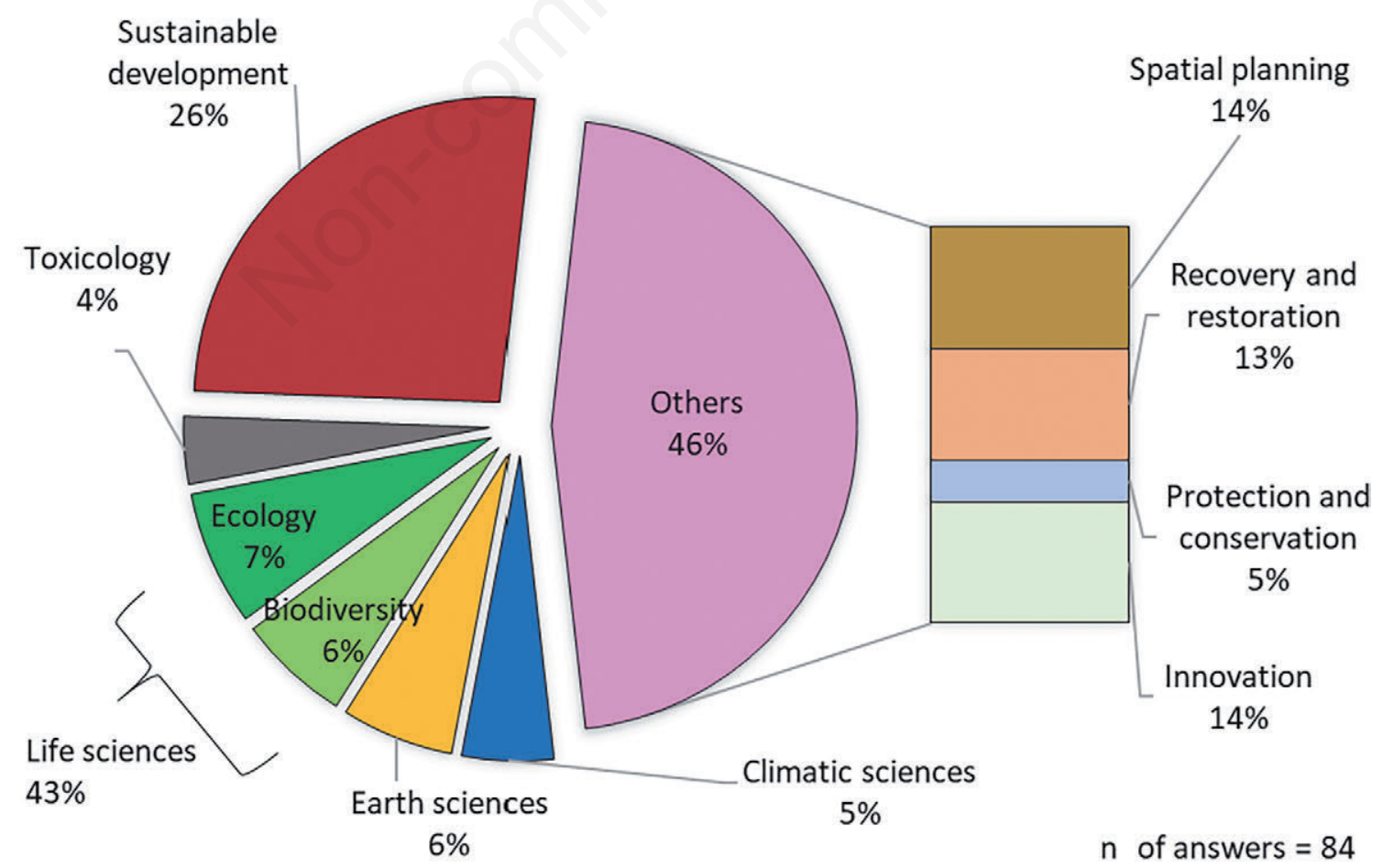

Fig. 10. Priority fields to invest in the next five years across the applied disciplines of aquatic sciences according to AIOL community. Values are in $\%$ of received answers. 
funded within the framework of R\&D collaboration projects is therefore highly desirable.

In addition, the Recovery and Restoration group (Fig. 10) included mainly: species responses in terms of production of secondary metabolites toxic and/or useful for humans, reduction of chemical and physical pollution/contamination in aquatic ecosystems, surface and groundwater depollution/depuration, containment of (micro)plastics and of emerging pollutant (CECs) diffusion, increase of treatment plants, ecotoxicology vs. oncology studies.

As for Protection and Conservation (Fig. 10), among the survey answers, we found issues such as the establishment of a network of protected areas, actions for biodiversity conservation, applied ecology and evolution, modeling of biogeochemical cycles, definition of ecological standard for water quality and quantity, effect of biodiversity loss on ecosystem functioning, microbiology, astrobiology.

Other examples of "hot" topics that should deserve the attention of national and international funding agencies, according to survey answers were: adaptation vs. mitigation measures to climate change, use of aquatic environments for the development of clean energy, process of reuse of natural resources and their protection, improved use of water in food and goods production, sustainable agriculture, aquaculture and fisheries, measures and technologies to preserve human and animal wellbeing, development of new technologies and platforms with low environmental impact, study of the impact on the environmental and architectural quality of cities by the widespread application of green techniques.

The number and complexity of the given answers confirms the multidisciplinary and interdisciplinary nature of aquatic science and the difficulty to focus on few key issues. The subsequent question we asked, about research topics addressed only to environmental management (Tab. 1), was therefore aimed at encouraging the AIOL community to deeply focus on this multidisciplinary and interdisciplinary nature of aquatic science to find connections and interactions among basic and applied research. The answers they provided (Fig. 11), grouped as the previous ones to allow a more precise comparison, suggest that the AIOL community has clear in mind the need to move toward a widespread sustainable approach (Sustainable development 18\%), that must be based on a better and severe scientific approach to land management (Earth sciences 18\%) and improvement of environmental quality (Toxicology $=8 \%$ ). The aim is to adopt a wise Spatial planning strategy (18\%), as a diffused and shared management tool, by also taking into consideration Recovery and Restoration (10\%) as well as Preservation and

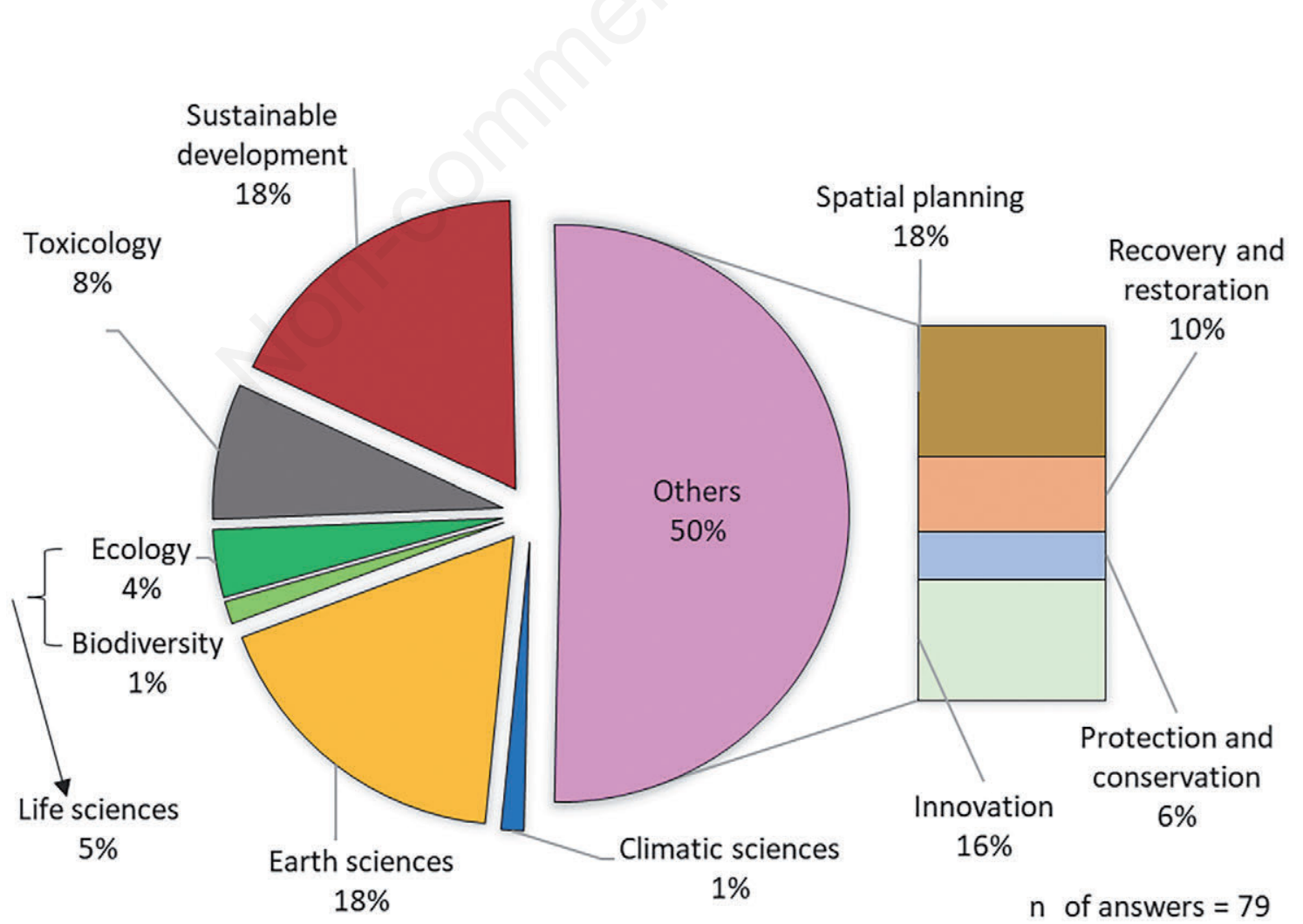

Fig. 11. Priority fields to invest in the next five years across the disciplines of aquatic sciences applied to environmental management, according to AIOL community (\% value of received answers). 
Conservation (6\%) actions. All this can and must be a strong push towards Innovation (16\%), not only in terms of instrumentations and technology, but also and above all in the way of thinking about the management of the territory and natural resources.

Given all that, why will civil society finance all this? What are the possible risks if we do not adopt this strategy or delay these interventions in favor of a more widespread and efficient research applied to land management? We provided a series of possible answers and an empty field for free answers. Survey answers (Fig. 12) suggested an awareness about the urgency to prevent a further deterioration of aquatic and terrestrial ecosystems and wetlands (15\%). But they were also focused on the need for a medium- to long-term vision (12\%), in which both critical approach and scientific knowledge are at the basis of the elaboration of sustainable management plans (11\%) to improve the status of aquatic ecosystems $(10 \%)$.

As a final remark, from the list of given answers (Fig. 12) we notice that they are often coupled twofold: one of them reflects a purely scientific motivation while the other contains a social implication, as if to testify the 'professional vs. personal' dual nature of each research scientist, who has to express her/himself on issues in which emotional involvement can play a fundamental role too. Some examples are (Fig. 12): i) to involve local communities in land participatory management (9\%) vs. to advance scientific knowledge on these topics (9\%); ii) to protect the status of aquatic and terrestrial ecosystems and wetlands $(6 \%)$ vs. to contribute to the construction of a shared system of rules based on the results of scientific research $(6 \%)$; iii) to promote and contribute to training new professionals (5\%) vs. to contribute to a widespread cultural growth of society $(5 \%)$.

\section{CONCLUSIONS}

The results of this survey allowed us to set the basis for a potential list of the priorities that funding agencies should include in their economic and financial planning of the next five years:

1) to promote and support sustainable food production (e.g., agriculture, aquaculture and fish farming), develop integrated and sustainable systems in aquaculture, boost the control of the food supplychain, etc.;

2) to promote and diffuse the spatial planning and integrated ecosystem-based management approach of maritime and terrestrial space by adopting and

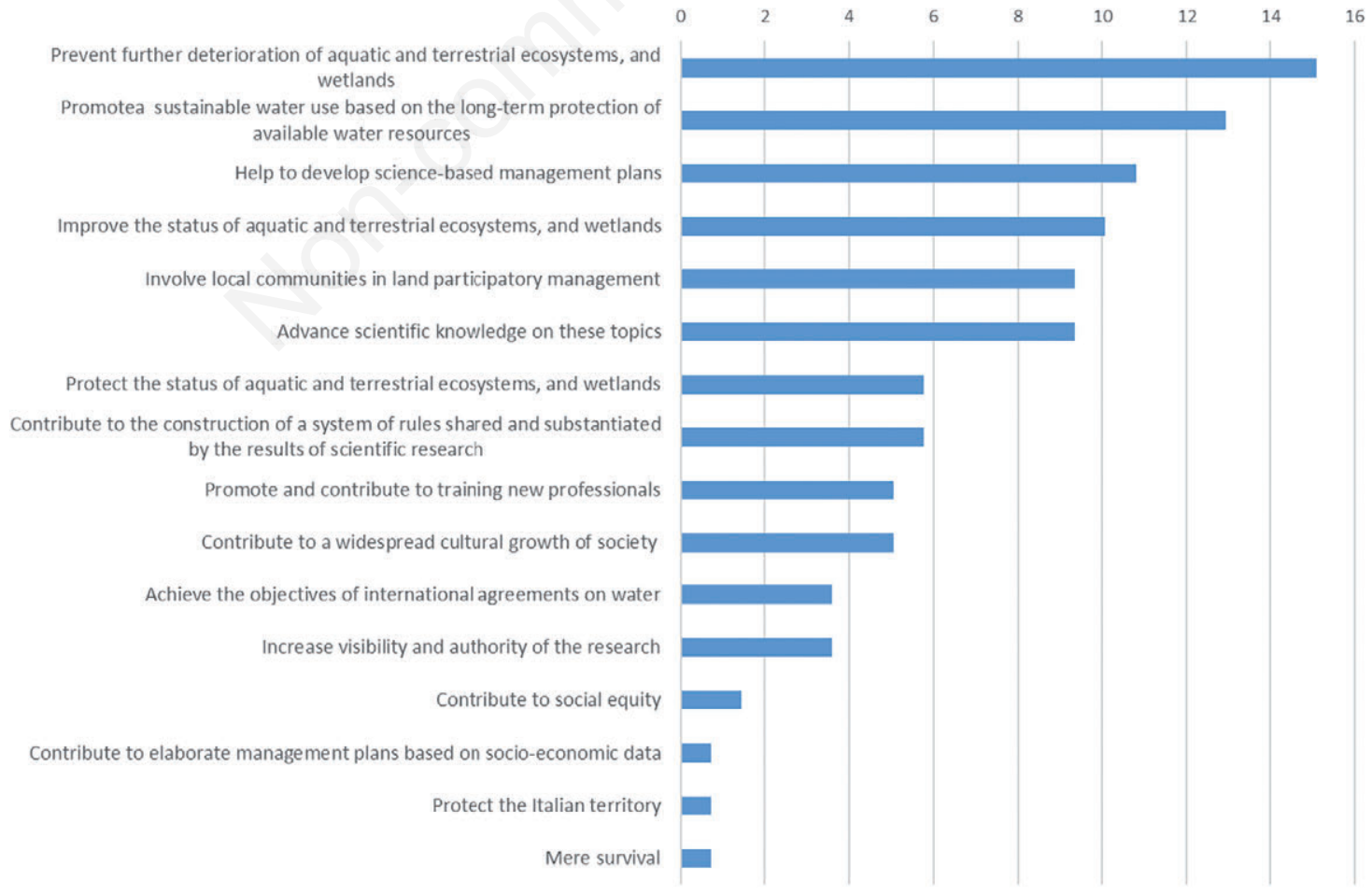

Fig. 12. Some reasons why the society should invest economic and financial resources in the next five years in these research fields, according to survey results. Values are in $\%$ of received answers. 
supporting positive actions for i) participatory democracy, ii) environmental control of urban settlements and landscape, iii) green and blue economy including energy, food supply and use of water resources, etc.;

3) to develop recovery/remediation plans for contaminated sites (e.g., by means of bioremediation), as well as intervention plans to i) counteract environmental degradation (terrestrial and marine) and hydrogeological instability, ii) assess CECs impact on ecosystems, iii) promote biological control of organisms harmful to agriculture and forest ecosystems, iv) limit the spread of ballast waters, etc.;

4) to promote conservation of ecosystems by i) assessing their conservation status, first of all the water quality, ii) evaluating and quantifying their ecosystem services, iii) applying a watershed ecology, iv) identifying of areas to be protected, even in deep marine environments, etc.;

5) to foster the technological development of sustainable and integrated tools and procedures for environmental monitoring aimed at i) ensuring ecosystem functionality, ii) identifying and minimizing the impact of anthropogenic pressures on aquatic systems, iii) developing recovering techniques for compromised aquatic environments in order to recover their ecosystem services, iv) applying realtime monitoring techniques (e.g., remote sensing) to water bodies in urban and peri-urban areas (e.g., mega-cities), etc.;

6) to develop a better forecasting capacity, particularly of extreme events, by i) implementing long-term research networks, ii) improving reliable predictive techniques of pressures entities, iii) developing modeling-methods based on geo-referenced systems in order to plan management and restoration actions of ecological quality, iv) implementing early warning systems, etc.;

7) to support training courses for professionals and a learning processes extended to a wider society, in order to i) promote new jobs, ii) further encourage interdisciplinary and multidisciplinary research, iii) achieve a more effective transfer of knowledge, iv) involve citizens in research (i.e., citizen science), v) promote social inclusion and culture, vi) evaluate ecosystem health, and finally vii) gain mutual understanding and interoperability between science and society.

\section{ACKNOWLEDGMENTS}

We wish to thank all the members of the Associazione Italiana di Oceanologia e Limnologia (AIOL) who participated to the Cagliari workshop and to the survey, and Antonio Pusceddu and Nico Salmaso for their support and the confidence placed in us.

\section{REFERENCES}

Albrecht J, 2016. Legal framework and criteria for effectively coordinating public participation under the Floods Directive and Water Framework Directive: European requirements and German transposition. Environ. Sci. Pol. 55:368-375.

Alpine Convention, 2009. Water and Water Management Issues - Report on the State of the Alps. Alpine Signals, Special Edition 2. Innsbruck.

Beniston M, Stephenson DB, Christensen OB, Ferro CA, Frei C, Goyette S, Halsnaes K, Holt T, Jylhä K, Koffi B, Palutikof J, 2007. Future extreme events in European climate: an exploration of regional climate model projections. Clim. Change 81:71-95.

Bertoni R, 2006. [Laghi e scienza - Introduzione alla limnologia].[Book in Italian]. Aracne Editrice, Roma.

Boero F, Bonsdorff E, 2007. A conceptual framework for marine biodiversity and ecosysm functioning. Mar. Ecol. 28: 34-145.

Boero F, Brotz L, Gibbons MJ, Piraino S, Zampardi S, 2016. Impacts and effects of ocean warming on jellyfish. Gland, Switzerland, IUCN: 213-237.

Bogdan A, Istudor N, Gruia R, Tobă GF, Bulz N, Gâf-Deac I, Chelmu S, Găvan C, Prică I and Paşalău C, 2014. New holistic approach of bioeconomics and ecoeconomics theories, practical bridging from the green economy to blue economy, trough new integrated and innovative paradigm about "bio-eco-geo-economy". Proc. Econ. Fin. 8:83-90.

Brack W, Dulio V, Ågerstrand M, Allan I, Altenburger R, Brinkmann M, Bunke D, Burgess RM, Cousins I, Escher BI, Hernández FJ, Hewitt LM, Hilscherová K, Hollender J, Hollert H, Kase R, Klauer B, Lindim C, Herráez DL, Miège C, Munthe J, O'Toole S, Posthuma L, Rüdel H, Schäfer RB, Sengl M, Smedes F, van de Meent D, van den Brink PJ, van Gils J, van Wezel AP, Vethaak AD, Vermeirssen E, von der Ohe PC, Vrana B, 2017. Towards the review of the European Union Water Framework management of chemical contamination in European surface water resources. Sci. Total Environ. 576:720-737.

Brock TD, 1985. Long-term Change in Lake Mendota. In: A eutrophic lake. Ecological studies (Analysis and Synthesis), 55. Springer, New York. doi.org/10.1007/978-1-44198700-6 9

Buttigieg PL, Fadeev E, Bienhold C, Hehemann L, Offre P, and Boetius A, 2018. Marine microbes in 4D - Using time series observation to assess the dynamics of the ocean microbiome and its links to ocean health. Curr. Opin. Microbiol. 43:169-185.

Buytaert W, Zulkafli Z, Grainger S, Acosta L, Alemie TC, Bastiaensen J, De Bièvre B, Bhusal J, Clark J, Dewulf A, Foggin M, Hannah DM, Hergarten C, Isaeva A, Karpouzoglou T, Pandeya B, Paudel D, Sharma K, Steenhuis T, Tilahun S, Van Hecken G, Zhumanova M, 2014. Citizen science in hydrology and water resources: opportunities for knowledge generation, ecosystem service management, and sustainable development. Front. Earth. Sci. 2:26. 
Cianelli D, D'Alelio D, Uttieri M, Sarno D, Zingone A, Zambianchi E, Ribera d'Alcalà M, 2017. Disentangling physical and biological drivers of phytoplankton dynamics in a coastal system. Sci. Rep. 7:15868.

Crain CM, Kroeker K, Halpern BS, 2011. Interactive and cumulative effects of multiple human stressors in marine systems. Ecol. Lett. 11:1304-1315.

D'Alelio D, Libralato S, Wyatt T, Ribera d'Alcalà M, 2016. Ecological-network models link diversity, structure and function in the plankton food-web. Sci. Rep. 6:21806.

Di Guardo A, Finizio A, 2016. A moni-modelling approach to manage groundwater risk to pesticide leaching at regional scale. Sci. Total Environ. 545/546:200-209.

Di Guardo A, Terzaghi E, Raspa G, Borin S, Mapelli F, Chouaia B, Zanardini E, Morosini C, Colombo A, Fattore E, Davoli E, Armiraglio S, Sale VM, Anelli S, Nastasio P, 2017. Differentiating current and past PCB and PCDD/F sources: the role of a large contaminated soil site in an industrialized city area. Environ. Poll. 223:367-375.

Dornburg V, Faaij APC, Verweij PA, Banse M. Diepen KV, Keulen HV, Langeveld H, Meeusen M, Ven GVD, Wester F, Alkemade R, 2008. Biomass assessment: assessment of global biomass potentials and their links to food, water, biodiversity, energy demand and economy: inventory and analysis of existing studies: supporting document (No. 500102 014), MNP.

Dickey T, 2009. Progress in multi-disciplinary sensing of the 4dimensional ocean. In: W. Hou (ed.), Ocean Sensing and Monitoring. SPIE Proceedings 7317:731702.

Duis K, Coors A, 2016. Microplastics in the aquatic and terrestrial environment: sources (with a specific focus on personal care products), fate and effects. Environ. Sci. Eur. $28: 2$.

Easterling DR, Meehl GA, Parmesan C, Changnon SA, Karl TR, Mearns LO, 2000. Climate extremes: observations, modeling, and impacts. Science 289:2068-2074.

Fattore E, Davoli E, Armiraglio S, Sale V M, Anelli S, Nastasio $\mathrm{P}, 2017$. Differentiating current and past PCB and PCDD/F sources: the role of a large contaminated soil site in an industrialized city area. Environ. Poll. 223:367-375.

Gamfeldt L, Lefcheck JS, Byrnes JEK, Cardinale BJ, Duffy JE, Griffin JN, 2015. Marine biodiversity and ecosystem functioning: what's known and what's next? Oikos 124:252265.

Glassmeyer ST, Furlong ET, Kolpin DW, Batt AL, Benson R, Boone JS, Conerly O, Donohue MJ, King DN, Kostich MS, Mash HE, Pfaller SL, Schenck KM, Simmons JE, Varughese EA, Vesper SJ, Villegas EN, Wilson VS, 2017. Nationwide reconnaissance of contaminants of emerging concern in source and treated drinking waters of the United States. Sci. Total Environ. 581/582:909-922.

Hall DM, Gilbertz SJ, Anderson MB, Ward LC, 2016. Beyond "buy-in": designing citizen participation in water planning as research. J. Clean Prod. 133: 25-734.

Hamilton DP, Wood SA, Dietrich DR, Puddick J, 2014. Costs of harmful blooms of freshwater cyanobacteria, P. 245-256. In: N.K. Sharma, A.K. Rai and L.J. Stal (eds.), Cyanobacteria: An economic perspective. J. Wiley \& Sons, Chichester.

Howarth R, Chan F, Conley DJ, Garnier J, Doney SC, Marino
R, Billen G, 2011. Coupled biogeochemical cycles: eutrophication and hypoxia in temperate estuaries and coastal marine ecosystems. Front. Ecol. Environ. 9:18-26.

Jacobs K, Lebel L, Buizer J, Addams L, Matson P, McCullough E, Garden P, Saliba G, Finan T, 2016. Linking knowledge with action in the pursuit of sustainable water-resources management. P. Natl. Acad. Sci. USA 113:4591-4596.

Mortara B, Gonzalez Verdesoto E, Barry G, 2014. Science for Disaster Risk Reduction. JRC Thematic Report, Publications Office of the European Union. doi: 10.2788/65084.

Kallf J, 2002. Limnology : inland water ecosystems. PrenticeHall, Inc., Upper Saddle River: 592 pp.

Lal R, 2004. Soil carbon sequestration impacts on global climate change and food security. Science 304:1623-1627.

Likens GE, 2009. Encyclopedia of inland waters. 1. Academic Press: $2250 \mathrm{pp}$.

Manca M, Calderoni A, Mosello R, 1992. Limnological research in Lago Maggiore: studies on hydrochemistry and plankton. Mem. Ist. It. Idrobiol. 50: 71-200.

Meriluoto J, Blaha L, Bojadzija G, Bormans M, Brient L, Codd GA, Drobac D, Faassen EJ, Fastner J, Hiskia A, Ibelings BW, Kaloudis T, Kokocinski M, Kurmayer R, Pantelić D, Quesada A, Salmaso N, Tokodi N, Triantis TM, Visser PM, Svirčev Z, 2017a. Toxic cyanobacteria and cyanotoxins in European waters - recent progress achieved through the CYANOCOST Action and challenges for further research. Adv. Ocean. Limnol. 8:161-178. doi: 10.4081/aiol.2017.6429

Meriluoto J, Spoof L, Codd GA, 2017b. Handbook on cyanobacterial monitoring and cyanotoxin analysis. Wiley: $576 \mathrm{pp}$.

Morabito G, Mazzocchi MG, Salmaso N, Zingone A, Bergami C, Flaim G, Accoroni S, Basset A, Bastianini M, Belmonte G, Bernardi Aubry F, Bertani I, Bresciani M, Buzzi F, Cabrini M, Camatti E, Caroppo C, Cataletto B, Castellano M, Del Negro P, de Olazabal A, Di Capua I, Elia AC, Fornasaro D, Giallain M, Grilli F, Leoni B, Lipizer M, Longobardi L, Ludovisi A, Lugliè A, Manca M, Margiotta F, Mariani MA, Marini M, Marzocchi M, Obertegger U, Oggioni A, Padedda BM, Pansera M, Piscia R, Povero P, Pulina S, Romagnoli T, Rosati I, Rossetti G, Rubino F, Sarno D, Satta CT, Sechi N, Stanca E, Tirelli V, Totti C, Pugnetti A, 2018. Plankton dynamics across the freshwater, transitional and marine research sites of the LTER-Italy Network. Patterns, fluctuations, drivers. Sci. Tot. Environ. 627: 73-387.

Mosello R, Calderoni A, de Bernardi R, 1997. Le indagini sulla evoluzione dei laghi profondi sudalpini svolte dal C.N.R. Istituto italiano di Idrobiologia. Docum. Ist. It. Idrobiol. 61:19-32.

Pauli GA, 2010. The blue economy: 10 years, 100 innovations, 100 million jobs. Paradigm Publications: 308 pp.

Pearce F, 2006. When the rivers run dry: Water - The defining crisis of the twenty-first century. Beacon Press: 336 pp.

Peters RH, 1990. Pathologies in limnology. Mem. Ist. It. Idriobiol. 47:181-217.

Postel S, Carpenter S, 1997. Freshwater ecosystem services., p. 195-214. In: G. Daily (ed.), Nature's Services: Societal dependence on natural ecosystems. Island Press, Washington, DC.

Reichman O J, Jones MB, Schildhauer MP, 2011. Challenges 
and opportunities of open data in ecology. Science 331:703705.

Rösch R, Baer J, Brinker A, 2017. Impact of the invasive threespined stickleback (Gasterosteus aculeatus) on relative abundance and growth of native pelagic whitefish (Coregonus wartmanni) in Upper Lake Constance. Hydrobiologia 1-12. doi: 10.1007/s10750-017-3479-6

Ruggiero MV, D’Alelio D, Ferrante MI, Santoro M, Vitale L, Procaccini G, Montresor M, 2018. Clonal expansion behind a marine diatom bloom. ISME J. 12:463-472.

Schindler DW, 2006. Recent advances in the understanding and management of eutrophication. Limnol. Oceanogr. 51: 356-363.

Science for Environment Policy, 2015. Migration in response to environmental change. Science Communication Unit (Ed.), UWE, Bristol 51: 16 pp.

Silver JJ, Gray NJ, Campbell LM, Fairbanks LW, Gruby RL, 2015. Blue economy and competing discourses in international oceans governance. J. Environ. Dev. 24(2):135160.

Thielen del Pozo J, Thiemig V, Pappenberger F, Revilla-Romero B, Salamon P, De Groeve T, Hirpa F, 2015. The benefit of continental flood early warning systems to reduce the impact of flood disasters. EUR $27533 \mathrm{EN}$; doi:10.2788/46941

Tyler AN, Hunter PD, Carvalho L, Codd GA, Elliott JA, Ferguson CA, Hanley ND, Hopkins DW, Maberly S C, Mearns KJ, Scott EM, 2009. Strategies for monitoring and managing mass populations of toxic cyanobacteria in recreational waters: a multi-interdisciplinary approach. Environ. Health 8:S11.

Verspagen JMHH, Van de Waal DB, Finke JF, Visser PM, Van Donk E, Huisman J, 2014. Rising $\mathrm{CO}_{2}$ levels will intensify phytoplankton blooms in eutrophic and hypertrophic lakes. PLoS One 9:e104325.

Vilà M, Basnou C, Pyšek P, Josefsson M, Genovesi, P, Gollasch S, Nentwig W, Olenin S, Roques A, Roy D, Hulme PE, 2010. How well do we understand the impacts of alien species on ecosystem services? A pan-European, cross-taxa assessment. Front. Ecol. Environ. 8:135-144.

Water Framework Directive, 2000. Directive 2000/60/EC of the European Parliament and of the Council of 23 October 2000 establishing a framework for Community action in the field of water policy. Official Journal of the European Parliament.

Wells ML, Karlson B, 2018. Harmful algal blooms in a changing ocean. In: P.M. Glibert, E. Berdalet, M.A. Burford, G.C. Pitcher, M. Zhou (eds.), Global Ecology and oceanography of harmful algal blooms. Springer: 77-90.

Wetzel RG, 2001. Limnology. Lake and river ecosystems. Academic Press, San Diego, USA: 1006 pp.

Williams WD, 2001. Anthropogenic salinisation of inland waters, p. 329-337. In: J.M. Melack, R. Jellison, D.B. Herbst (eds.), Saline lakes. Developments in hydrobiology. Springer, Dordrecht. 